\title{
SIFAT-SIFAT YANG TERKAIT DENGAN MATRIKS IDEMPOTEN
}

\author{
MELATI SRI WAHYUNI, NOVA NOLIZA BAKAR, YANITA \\ Program Studi S1 Matematika, \\ Fakultas Matematika dan Ilmu Pengetahuan Alam, Universitas Andalas, \\ Kampus UNAND Limau Manis Padang, Indonesia. \\ email : melatisriwahyuni@gmail.com
}

Diterima 9 Maret 2019 Direvisi 7 April 2019 Dipublikasikan 7 Mei 2019

\begin{abstract}
Abstrak. Suatu matriks $A$ berukuran $n \times n$ dikatakan matriks idempoten jika $A^{2}=A$. Tulisan ini membahas tentang sifat-sifat yang terkait dengan matriks idempoten yang meliputi keterkaitan antara matriks idempoten dengan matriks ortogonal, simetri, involutori, dan invers Moore Penrose, serta membahas sifat-sifat ruang kolom, ruang null, rank dan trace dari matriks tersebut.
\end{abstract}

Kata Kunci: Matriks Idempoten, Invers Moore-Penrose, Rank

\section{Pendahuluan}

Teori matriks merupakan salah satu cabang ilmu aljabar linier yang menjadi pembahasan dalam ilmu matematika. Matriks adalah susunan empat persegi panjang atau bujursangkar yang disusun dalam bentuk baris dan kolom. Bilangan-bilangan yang terdapat disuatu matriks disebut dengan entri matriks. Matriks biasanya disimbolkan dengan huruf besar yaitu $A=\left[a_{i j}\right], a_{i j}$ entri pada $A[1]$.

Ada beberapa jenis matriks dengan sifat khusus, salah satu diantaranya adalah matriks idempoten. Matriks idempoten $A$ adalah matriks yang apabila dikalikan dengan dirinya sendiri merupakan matriks itu sendiri atau $A^{2}=A$. Matriks idempoten mempunyai peran penting dalam teori model statistika linier, terutama dalam kaitannya dengan teori kuadrat terkecil dan analisis varians. Oleh karena itu pada skripsi ini akan dibahas sifat-sifat yang terkait dengan matriks idempoten.

Secara umum matriks yang bukan idempoten jika dioperasikan dengan matriks lainnya akan menghasilkan matriks baru dan terdapat sifat-sifat yang dapat disimpulkan dengan matriks tersebut. Oleh karena matriks idempoten $A$ mempunyai sifat $A^{2}=A$ maka pada skripsi ini yang menjadi rumusan masalah adalah bagaimanakah sifat-sifat matriks idempoten jika dioperasikan dengan matriks lainnya, serta sifatsifat ruang null, ruang kolom, rank dan trace dari matriks idempoten tersebut.

Adapun tujuan dari penulisan tulisan ini adalah menentukan keterkaitan matriks idempoten dengan matriks lainnya dan mengkaji sifat-sifat ruang null, ruang kolom, rank dan trace dari matriks idempoten. 
202 Melati Sri Wahyuni dkk.

\section{Landasan Teori}

\subsection{Teori Matriks}

Definisi 2.1. [1] Matriks adalah jajaran empat persegi panjang dari bilanganbilangan. Bilangan-bilangan dalam jajaran tersebut dinamakan entri dari matriks.

Definisi 2.2. [4] Suatu matriks A berukuran $n \times n$ dikatakan matriks involutori jika $A^{2}=I_{n}$.

Definisi 2.3. [1] Jika A adalah matriks berukuran $m \times n$, maka transpos dari $A$ dinyatakan dengan $A^{T}$ didefinisikan sebagai matriks $n \times m$ didapatkan dengan mempertukarkan baris dan kolom dari A sehingga kolom pertama dari $A^{T}$ adalah baris pertama dari $A$, kolom kedua dari $A^{T}$ adalah baris kedua dari $A$, dan seterusnya.

Teorema 2.4. [1] Misalkan matriks A dan B berukuran sama, sedemikian sehingga operasi-operasi berikut dapat dilakukan dan misalkan $k$ adalah skalar, maka:

a. $\left(A^{T}\right)^{T}=A$,

b. $(A+B)^{T}=A^{T}+B^{T}$ dan $(A-B)^{T}=A^{T}-B^{T}$,

c. $(k A)^{T}=k A^{T}$ dengan $k$ adalah skalar sebarang,

d. $(A B)^{T}=B^{T} A^{T}$.

Definisi 2.5. [1] Matriks A berukuran $n \times n$ disebut simetris jika $A=A^{T}$.

Definisi 2.6. [1] Sebuah matriks bujursangkar A yang memiliki sifat $A^{-1}=A^{T}$ disebut sebagai matriks ortogonal.

Dari Definisi 2.6 sebuah matriks bujursangkar $A$ ortogonal jika dan hanya jika $A A^{T}=A^{T} A=I$.

Definisi 2.7. [1] Jika A adalah matriks dengan elemen bilangan kompleks, maka transpos konjugat dari $A$ dinotasikan dengan $A *$, disimbolkan oleh $A^{*}=A^{-T}$, dimana $A^{-}$adalah matriks yang entrinya merupakan konjugat kompleks dari entri yang bersesuaian di $A$ dan $A^{-T}$ adalah transpos dari $A^{-}$.

Definisi 2.8. [1] Jika A adalah sebuah matriks berukuran $n \times n$, maka trace dari $A$, yang dinyatakan sebagai $\operatorname{tr}(A)$, didefinisikan sebagai jumlah entri-entri pada diagonal utama matriks $A$.

Lema 2.9. [4] Misalkan $A$ dan $B$ matriks berukuran $n \times n$, maka

$$
\operatorname{tr}(A+B)=\operatorname{tr}(A)+\operatorname{tr}(B) \text { dan } \operatorname{tr}(A-B)=\operatorname{tr}(A)-\operatorname{tr}(B) .
$$

Definisi 2.10. [4] Misalkan A matriks berukuran $m \times n$ dan matriks $B$ berukuran $n \times m, m a k a$

$$
\operatorname{tr}(A B)=\operatorname{tr}(B A)
$$

Definisi 2.11. [6] Suatu matriks $A$ berukuran $n \times n$ dikatakan taksingular atau dapat dibalik (invertible) jika terdapat matriks $B$, sehingga

$$
A B=B A=I .
$$


Matriks $B$ disebut invers dari $A$.

Definisi 2.12. [4] Misalkan A adalah matriks berukuran $m \times n$. Matriks $B$ dengan ukuran $n \times m$ dikatakan invers kiri dari $A$ jika $B A=I_{n}$ dan matriks $C$ dengan ukuran $n \times m$ dikatakan invers kanan dari $A$ jika $A C=I_{m}$.

\subsection{Rank Matriks}

Definisi 2.13. [1] Untuk suatu matriks berukuran $m \times n$ berikut

$$
\left[\begin{array}{cccc}
a_{11} & a_{12} & \cdots & a_{1 n} \\
a_{21} & a_{22} & \cdots & a_{2 n} \\
\vdots & \vdots & \ddots & \vdots \\
a_{m 1} & a_{m 2} & \cdots & a_{m n}
\end{array}\right]
$$

vektor-vektor

$$
\begin{gathered}
\boldsymbol{r}_{1}=\left(a_{11}, a_{12}, \ldots, a_{1 n}\right) \\
\boldsymbol{r}_{2}=\left(a_{21}, a_{22}, \ldots, a_{2 n}\right) \\
\vdots \\
\boldsymbol{r}_{m}=\left(a_{m 1}, a_{m 2}, \ldots, a_{m n}\right)
\end{gathered}
$$

disebut vektor-vektor baris A. Dan ruang yang dibangun oleh vektor-vektor baris ini disebut ruang baris $A$ dinyatakan sebagai $R(A)$. Sedangkan vektor-vektor

$$
\begin{gathered}
\boldsymbol{c}_{1}=\left(a_{11}, a_{21}, \ldots, a_{m 1}\right) \\
\boldsymbol{c}_{2}=\left(a_{12}, a_{22}, \ldots, a_{m 2}\right) \\
\vdots \\
\boldsymbol{c}_{n}=\left(a_{1 n}, a_{2 n}, \ldots, a_{m n}\right)
\end{gathered}
$$

disebut vektor-vektor kolom $A$ dan ruang yang dibangun oleh vektor-vektor kolom ini disebut ruang kolom $A$ dinyatakan sebagai $C(A)$.

Lema 2.14. [4] Untuk sebarang matriks $A$ berukuran $m \times n$ dan matriks $B$ berukuran $m \times p, C(B) \subset C(A)$ jika dan hanya jika terdapat matriks $F$ berukuran $n \times p$ sedemikian sehingga $B=A F$.

Definisi 2.15. [1] Misalkan $A$ adalah suatu matriks berukuran $m \times n$. Ruang solusi dari sistem persamaan yang homogen $A x=\mathbf{0}$, yang merupakan subruang dari $\mathbb{R}^{n}$, disebut ruang null dari $A$ dinyatakan sebagai $N(A)$.

Definisi 2.16. [1] Dimensi dari ruang baris dan ruang kolom dari suatu matriks $A$ disebut rank dari $A$ dan dinyatakan sebagai $r k(A)$. Dimensi dari ruang null dari matriks $A$ disebut nulitas dari $A$ dinyatakan sebagai nlty $(A)$.

Teorema 2.17. [7] Untuk ruang vektor $L$ dan $N$ sedemikian sehingga $L \subseteq N$ pernyataan di bawah ini adalah benar.

(1) $\operatorname{dim}(L) \leq \operatorname{dim}(N)$. 
204 Melati Sri Wahyuni dkk.

(2) $\operatorname{Jika} \operatorname{dim}(L)=\operatorname{dim}(N)$, maka $L=N$.

Lema 2.18. [4] Untuk sebarang matriks $A$ berukuran $m \times n, r k(A) \leq m$ atau $r k(A) \leq n$.

Teorema 2.19. [4] Misalkan $A$ matriks berukuran $m \times n$ dan $B$ matriks berukuran $m \times p$. Jika $C(B) \subset C(A)$ maka $r k(B) \leq r k(A)$.

Akibat 2.20. [4] Untuk sebarang matriks $A$ berukuran $m \times n$ dan matriks $F$ beruku$\operatorname{ran} n \times p, r k(A F) \leq r k(A) \operatorname{dan} r k(A F) \leq r k(F)$.

Akibat 2.21. [4] Misalkan $A$ matriks berukuran $m \times n$ dan $F$ matriks berukuran $n \times p$. Jika $r k(A F)=r k(A) \operatorname{maka} C(A F)=C(A)$.

Akibat 2.22. [4] Untuk sebarang matriks $A$ dan $B$ berukuran $m \times n$, maka $r k(A+$ $B) \leq r k(A)+r k(B)$.

Teorema 2.23. [1] Jika $A$ adalah suatu matriks dengan n kolom, maka

$$
r k(A)+\operatorname{nlty}(A)=n .
$$

Definisi 2.24. [4] Suatu matriks A berukuran $m \times n$ dikatakan mempunyai rank kolom penuh jika $r k(A)=n$ dan rank baris penuh jika $r k(A)=m$.

Teorema 2.25. [4] Setiap ruang vektor dari matriks berukuran $m \times n$ mempunyai basis.

Teorema 2.26. [4] Misalkan A matriks berukuran $m \times n$ dan tidak nol, dengan $r k(A)=r$. Maka, terdapat suatu matriks $B$ berukuran $m \times r$ dan matriks $L$ berukuran $r \times n$, sedemikian sehingga $A=B L$.

Teorema 2.27. [4] Misalkan $A$ matriks berukuran $m \times n$ dan tidak nol, dengan $r k(A)=r$, maka terdapat suatu matriks $B$ berukuran $m \times r$ dan matriks $T$ berukuran $r \times n$, sedemikian sehingga $A=B T \operatorname{dan} r k(B)=r k(T)=r$.

Lema 2.28. [4] Matriks A berukuran $m \times n$ mempunyai invers kanan jika dan hanya jika $r k(A)=m$. Dan mempunyai invers kiri jika dan hanya jika $r k(A)=n$.

Lema 2.29. [4] Misalkan $A$ dan $B$ matriks berukuran $m \times n$. Untuk sebarang matriks $C$ berukuran $r \times m$ yang mempunyai rank kolom penuh dan untuk sebarang matriks $D$ berukuran $n \times p$ yang mempunyai rank baris penuh, maka berlaku

(1.) Jika $C A=C B$, maka $A=B$.

(2.) Jika $A D=B D$, maka $A=B$.

(3.) Jika $C A D=C B D$, maka $A=B$.

\subsection{Persamaan Penrose}

Pada tahun 1955, Penrose [2] menunjukkan bahwa untuk setiap matriks $A$ dengan elemen riil atau kompleks, terdapat matriks tunggal $X$ sehingga memenuhi empat 
persamaan yang dikenal sebagai persamaan Penrose. Persamaan inilah yang menjadi dasar adanya generalisasi invers suatu matriks. Generalisasi invers merupakan perluasan dari konsep invers matriks. Empat persamaan Penrose tersebut adalah:

$$
\begin{array}{r}
A X A=A \\
X A X=X \\
(A X)^{*}=A X \\
(X A)^{*}=X A
\end{array}
$$

dimana $A$ suatu matriks berukuran $m \times n$ dan $X$ matriks berukuran $n \times m$. Matriks $X$ yang memenuhi keempat persamaan di atas, disebut invers Moore Penrose, disimbolkan dengan $X=A^{+}$.

\subsection{Matriks Idempoten}

Definisi 2.30. [4] Suatu matriks $A$ berukuran $n \times n$ dikatakan matriks idempoten jika

$$
A^{2}=A \text {. }
$$

Teorema 2.31. [4] Misalkan $A$ dan $B$ matriks idempoten $n \times n$, maka $A+B$ merupakan matriks idempoten, jika dan hanya jika $A B=B A=\mathbb{O}$.

Lema 2.32. [4] Misalkan A matriks idempoten berukuran $n \times n$, jika dan hanya jika $I-A$ adalah matriks idempoten.

\section{Pembahasan}

\subsection{Sifat-Sifat Matriks Idempoten Terkait dengan Matriks lainnya}

Berikut ini akan dibahas beberapa sifat-sifat operasi matriks idempoten dengan matriks lainnya.

Lema 3.1. [4] Misalkan A adalah matriks idempoten berukuran $n \times n$. Maka, untuk sebarang matriks nonsingular $B$ berukuran $n \times n$, maka $B^{-1} A B$ adalah idempoten.

Lema 3.2. [4] Jika A adalah matriks idempoten yang simetris, maka I-2A adalah ortogonal.

Lema 3.3. [4] Misalkan A matriks berukuran $n \times n$. Maka berlaku, $\frac{1}{2}(I+A)$ adalah matriks idempoten jika dan hanya jika $A$ adalah matriks involutori.

Lema 3.4. [4] Misalkan $A$ dan $B$ adalah matriks simetris yang idempoten. Jika $C(A)=C(B)$, maka $A=B$.

Bukti. Misalkan $A$ dan $B$ adalah matriks simetris yang idempoten dengan $C(A)=$ $C(B)$. Akan dibuktikan $A=B$. Dari $C(A)=C(B)$ diperoleh $C(A) \subset C(B)$ dan $C(B) \subset C(A)$. Berdasarkan Lema 2.14 karena $C(A) \subset C(B)$, maka terdapat matriks $R$ berukuran $n \times n$, sedemikian sehingga $A=B R$. Dan berdasarkan Lema 
206 Melati Sri Wahyuni dkk.

2.14 karena $C(B) \subset C(A)$, maka terdapat matriks $S$ berukuran $n \times n$, sedemikian sehingga $B=A S$. Perhatikan bahwa,

$$
\begin{aligned}
B & =B^{T}, \\
& =(A S)^{T}, \quad \text { dari Teorema } 2.4(\mathrm{~d}), \\
& =S^{T} A^{T} \\
& =S^{T} A .
\end{aligned}
$$

Selanjutnya,

$$
\begin{aligned}
A & =B R, \text { dari Definisi } 2.30, \\
& =B^{2} R, \\
& =B B R, \\
& =B A, \\
& =S^{T} A A, \\
& =S^{T} A^{2}, \text { dari Definisi } 2.30, \\
& =S^{T} A .
\end{aligned}
$$

Oleh karena itu, $B=A$.

Lema 3.5. [4] Misalkan $A$ matriks berukuran $m \times n$. Maka $A^{+} A$ yang merupakan matriks berukuran $n \times n$ dan $A A^{+}$yang berukuran $m \times m$, keduanya adalah matriks idempoten.

\subsection{Sifat-Sifat Ruang Null, Ruang Kolom, Rank dan Trace dari Matriks Idempoten}

Teorema 3.6. [4] Untuk sebarang matriks $A$ berukuran $n \times n$, jika $A^{2}=k A$ untuk suatu skalar $k$, maka

$$
\operatorname{tr}(A)=\operatorname{krk}(A)
$$

Akibat 3.7. Untuk sebarang matriks idempoten $A$ berukuran $n \times n$, maka

$$
r k(A)=\operatorname{tr}(A) .
$$

Teorema 3.8. [4] Misalkan $A$ matriks berukuran $n \times n$. Maka berlaku, $N(A)=$ $C(I-A)$ jika dan hanya jika $A$ adalah matriks idempoten.

Teorema 3.9. [4] Untuk sebarang matriks $A$ berukuran $n \times n$, jika $A^{2}=k A$ untuk suatu skalar $k$, maka

$$
\operatorname{tr}(A)=\operatorname{krk}(A)
$$

Bukti. Misalkan $A$ matriks berukuran $n \times n$.

$(\Rightarrow$ ) Misalkan $N(A)=C(I-A)$. Akan dibuktikan $A$ adalah matriks idempoten. Perhatikan bahwa,

$$
\begin{aligned}
N(A) & =\left\{x \in \mathbb{R}^{n \times 1} \mid A x=\mathbf{0}\right\} \\
& =\left\{x \in \mathbb{R}^{n \times 1} \mid(I-A) x=x\right\} .
\end{aligned}
$$


Dari (3.1) dan (3.2) diperoleh $\mathbf{0}=A x=A(I-A) x$. Jadi, $A(I-A) x=\mathbf{0}$ untuk $x \in \mathbb{R}^{n \times 1}$, sehingga diperoleh $A(I-A)=\mathbb{O}$. Akibatnya $A^{2}=A$ atau $A$ adalah matriks idempoten.

$(\Leftarrow)$ Misalkan $A$ matriks idempoten. Akan dibuktikan $N(A)=C(I-A)$. Berdasarkan Teorema 2.23 diperoleh $n l t y(A)=n-r k(A)$. Perhatikan bahwa,

$$
\begin{aligned}
\operatorname{dim}(N(A)) & =n-r k(A), \\
& =r k(I)-r k(A), \quad \text { dari Akibat 3.7, } \\
& =\operatorname{tr}(I)-\operatorname{tr}(A), \quad \text { dari Lema 2.9, } \\
& =\operatorname{tr}(I-A), \text { dari Lema } 2.32 \text { dan Akibat 3.7, } \\
& =r k(I-A), \quad \text { dari Definisi } 2.16 \\
& =\operatorname{dim}(C(I-A)) .
\end{aligned}
$$

Dari (3.1) dan (3.2) untuk setiap $x \in \mathbb{R}^{n \times 1},(I-A) x \in N(A)$ atau $A x=A(I-A) x=$ 0. Karena $A(I-A) x=\mathbf{0}$, maka untuk sebarang $x \in \mathbb{R}^{n \times 1},(I-A) x \in C(I-A)$. Oleh karena itu, $N(A) \subset C(I-A)$. Dan berdasarkan Teorema 2.17 karena $N(A) \subset$ $C(I-A)$ dan $\operatorname{dim}(N(A))=\operatorname{dim}(C(I-A))$, maka $N(A)=C(I-A)$.

Akibat 3.10. [4] Misalkan A matriks berukuran $n \times n$. Maka berlaku, $C(A)=$ $N(I-A)$ jika dan hanya jika $A$ adalah matriks idempoten.

Lema 3.11. [4] Misalkan A suatu matriks berukuran $n \times n$. A matriks idempoten jika dan hanya jika $r k(A)+r k(I-A)=n$.

Lema 3.12. [4] Misalkan A matriks berukuran $m \times n$. Maka

(a.) $\operatorname{rk}\left(A^{+} A\right)=\operatorname{tr}\left(A^{+} A\right) \operatorname{dan} r k\left(A A^{+}\right)=\operatorname{tr}\left(A A^{+}\right)$.

(b.) $r k\left(I-A^{+} A\right)=\operatorname{tr}\left(I-A^{+} A\right)=n-r k\left(A^{+} A\right)$.

(c.) $r k\left(I-A A^{+}\right)=\operatorname{tr}\left(I-A A^{+}\right)=m-r k\left(A A^{+}\right)$.

Teorema 3.13. [4] Misalkan $A_{1}, A_{2}, \cdots, A_{k}$ matriks berukuran $n \times n$ dan misalkan $A=A_{1}+. A_{2}+\cdots+A_{k}$ dan $A$ adalah matriks idempoten. Maka, pernyataan berikut ekivalen.

(1) $A_{i} A_{j}=\mathbb{O}$ untuk $j \neq i=1,2, \cdots, k \operatorname{dan} r k\left(A_{i}{ }^{2}\right)=r k\left(A_{i}\right)$ untuk $i=1,2, \cdots, k$.

(2) $A_{i}{ }^{2}=A_{i}$ untuk $i=1,2, \cdots, k$.

(3) $r k\left(A_{1}\right)+r k\left(A_{2}\right)+\cdots+r k\left(A_{k}\right)=r k(A)$.

\section{Kesimpulan}

Berdasarkan pembahasan tentang sifat-sifat yang terkait dengan matriks idempoten dapat disimpulkan bahwa:

(1) Sifat-sifat matriks idempoten terkait dengan matriks lainnya yaitu:

(a) Misalkan $A$ adalah matriks idempoten berukuran $n \times n$. Maka, untuk sebarang matriks nonsingular $B$ berukuran $n \times n$, maka $B^{-1} A B$ adalah idempoten. 
(b) Jika $A$ adalah matriks idempoten yang simetris, maka $I-2 A$ adalah ortogonal.

(c) Misalkan $A$ matriks berukuran $n \times n$. Maka berlaku, $\frac{1}{2}(I+A)$ adalah matriks idempoten jika dan hanya jika $A$ adalah matriks involutory.

(d) Misalkan $A$ dan $B$ adalah matriks simetris yang idempoten. Jika $C(A)=$ $C(B)$ maka $A=B$.

(e) Misalkan $A$ matriks berukuran $m \times n$. Maka $A^{+} A$ yang merupakan matriks berukuran $n \times n$ dan $A A^{+}$yang berukuran $m \times m$, keduanya adalah matriks idempoten.

(2) Sifat-sifat ruang null, ruang kolom, rank dan trace dari matriks idempoten.

(a) Untuk sebarang matriks idempoten $A$ berukuran $n \times n$, maka

$$
\operatorname{rk}(A)=\operatorname{tr}(A) .
$$

(b) Misalkan $A$ matriks berukuran $n \times n$. Maka berlaku, $N(A)=C(I-A)$ jika dan hanya jika $A$ adalah matriks idempoten.

(c) Misalkan $A$ matriks berukuran $n \times n$. Maka berlaku, $C(A)=N(I-A)$ jika dan hanya jika $A$ adalah matriks idempoten.

(d) Misalkan $A$ suatu matriks berukuran $n \times n$. $A$ matriks idempoten jika dan hanya jika $r k(A)+r k(I-A)=n$.

(e) Misalkan A matriks berukuran $m \times n$. Maka

(i) $r k\left(A^{+} A\right)=\operatorname{tr}\left(A^{+} A\right) \operatorname{dan} r k\left(A A^{+}\right)=\operatorname{tr}\left(A A^{+}\right)$.

(ii.) $r k\left(I-A^{+} A\right)=\operatorname{tr}\left(I-A^{+} A\right)=n-r k\left(A^{+} A\right)$.

(ii.) $r k\left(I-A A^{+}\right)=\operatorname{tr}\left(I-A A^{+}\right)=m-r k\left(A A^{+}\right)$.

(f) Misalkan $A_{1}, A_{2}, \cdots, A_{k}$ matriks berukuran $n \times n$ dan misalkan $A=A_{1}+$ $A_{2}+\cdots+A_{k}$ dan $A$ adalah matriks idempoten. Maka pernyataan berikut ekivalen.

(i) $A_{i} A_{j}=\mathbb{O}$ untuk $j \neq i=1,2, \cdots, k$ dan $r k\left(A_{i}{ }^{2}\right)=r k\left(A_{i}\right)$ untuk $i=$ $1,2, \cdots, k$.

(ii) $A_{i}{ }^{2}=A_{i}$ untuk $i=1,2, \cdots, k$.

(iii) $r k\left(A_{1}\right)+r k\left(A_{2}\right)+\cdots+r k\left(A_{k}\right)=r k(A)$.

\section{Daftar Pustaka}

[1] Anton, H., C. Rorres. 2004. Aljabar Linier Elementer(terjemahan). Edisi 8. Jilid 1. Erlangga, Jakarta

[2] Ben-Israel, A., T.N.E. Greville. 2003. Generalized Inverses Theory and Application. Edisi 2. Springer-Verlag, New York

[3] Campbell, S.L. dan Meyer, C.D. 2009. Generalized Inverses of Linear Tranformations. SIAM

[4] Harville, D.A. 2008. Matrix Algebra from a Statistician's Perspective. Springer, New York

[5] Jacob, B. 2003. Linear Algebra. Mc Graw-Hill, New York

[6] Leon, S.J. 2001. Aljabar Linier dan Aplikasinya (terjemahan). Edisi 5. Erlangga, Jakarta

[7] Meyer, C. D. 2000. Matrix Analysis and Applied Linear Algebra. SIAM 